\title{
Business Owners' Feedback toward Adoption of Open Data: A Case Study in Kuwait
}

\author{
Nayef Alawadhi $\left(\mathbb{D},{ }^{1}\right.$ Imad Al Shaikhli $\left(\mathbb{D},{ }^{1}\right.$ Abdulrahman Alkandari $(\mathbb{D})^{2}$ \\ and Siba Kalaie Chab $\mathbb{D D}^{2}$ \\ ${ }^{1}$ Computer Science Department, KICT IIUM, Selangor, Malaysia \\ ${ }^{2}$ Computer Department, CBE PAAET, Shuwaikh, Kuwait
}

Correspondence should be addressed to Nayef Alawadhi; alawadhi.nayef@live.iium.edu.my

Received 26 December 2020; Revised 20 April 2021; Accepted 3 May 2021; Published 17 May 2021

Academic Editor: Yang Li

Copyright (c) 2021 Nayef Alawadhi et al. This is an open access article distributed under the Creative Commons Attribution License, which permits unrestricted use, distribution, and reproduction in any medium, provided the original work is properly cited.

\begin{abstract}
The world intention toward open data technology has increased in the past years, and governments started to explore open data technology in the public and private sectors and tried to check its advantages and disadvantages. However, in the Arab world and especially in Kuwait, there is no solid structured attention about the technology in both sectors. As a result, we tried in this paper to determine if business owners in Kuwait have enough knowledge of the open data (OD) concept and if they have the willingness to use it for enhancing their services. The purpose of this research is to measure the acceptance of OD technology in Kuwait and to gather business owners' opinions about the ability to adopt the OD concept. Making online and hardcopy survey was our method for gathering different reactions and points of view about this technology. We intended to focus on the private sector and we targeted people who own a business and wish to introduce better services for their customers. Overall, the results have shown clear features about open data technology in Kuwait and the substantial need of education and awareness of the importance of this technology. The results of this study may positively and directly affect the level of motivation for other existing studies.
\end{abstract}

\section{Introduction}

xBusiness owners are trying to find the best solutions to make rabid changes in their business field and to use various ways to introduce the best services for their customers and to provide a better labor environment to their employees. In addition, with the rising of development and discovering new technologies to get the high quality of the introduced products, open data (OD) has emerged to be one of the most important technologies all over the world in many places and involved to make the data available in business field to be known as business data (BD) aka open commercial data. Open data points to reutilize and change the data and information by anybody with beneficial purposes for different sectors under certain constraints. A research has introduced open data as to be used with a high standard of nation interest that is held by national, local, and other government proxies obtainable on the global network which is the Internet so that it can be accessed by all individuals [1]. The ability to use data again and enhance the quality of it is the main idea of this concept. Open data technology can unlock opportunities for young workers and offer new investments between companies. Open data technology has been found in different fields such as information technology (IT), science, and health [2]. The goal of open data technology is to get benefit from the nonindividual and nonmerchant information into data that can be used again by everyone. In 2006, and according to Tim, Berners-Lee, he published a deployment scheme for open data, based on five-incremental and progressively demanding-requirements represented as "stars" (BernersLee) [3]. A 5-star open dataset should comply with all these requirements:

(1) Available on the web, any format of provided data has an open license.

(2) Be available as machine-readable structured data (e.g., Excel instead of image scan). 
(3) Use available nonproprietary formats (e.g., CSV instead of Excel).

(4) Use open standards from W3C (RDF and SPARQL) and URIs to identify things.

(5) Link data to other providers' data to provide context.

Adopting open data technology to decision makers and accepting it need some courage to implement. To get the best advantages of open data, there must be some conditions to exploit open data technology in a proper way. Open data technology needs lots of support and acceptance from the government in Kuwait to be applied and get the best results. Open data must be provided for users to get the possible advantages from using the technology. Users must have these characteristics intended use, subject determination that the data will be used for technical talents.

Figure 1 depicts OD value chain and business model (BM). Concentrating on the business owners and the private sector, the discussion about which business models can be used and implemented in the exploitation of open data mainly applies to private sector for profit organizations as they are the players to be more challenged by finding a financial sustainability in leveraging a public good. The outcomes of this process are raw data, refined data, and "fitfor-purpose" products and services [4].

The major contributions of this research are twofold. First, major literature concentrated on Open Government Data (OGD) as major pillars for an open data ecosystem. Some challenged researches covered open commercial data; however, their focus was on how business owners utilize the OGD for their business advantages. Moreover, researches did not explicitly investigate the willingness of private sectors for adopting OD (as OD suppliers). Such an adoption can have an impact on shaping OD ecosystem especially in smart city environment. Therefore, there was a need for understanding if business owners are ready to have their data open to improve their productivity and profitability. Second, there are researches, for example, the one in [6], targeting open data in smart cities; however, these researches highly depend on business owners acceptance of OD. Accordingly, there is a need to conduct a preliminary survey that answers such a question. Third, a current study is in progress to develop a commercial recommendation system. This study utilizes OD from business owners in Kuwait. On this regard, many researches were done on Gulf Cooperation Council; however, to the best of our knowledge there was no study dedicated in Kuwait to investigate business owners' point of view on OD adoption. As a result, this study is presented to acquire direct answers from business owners for the acceptance of OD.

This research is structured as follows: part 1 is the introduction followed by part 2 discussing literature review. Section 3 focuses on study hypothesis, part 4 shows survey methodology and data analysis, part 5 previews findings and discussions, part 6 focuses on implications of our study, and part 7 provides conclusions and future thoughts about the usefulness of open data for business owners and its future in Kuwait.

\section{Related Work}

With the intensive search and the available researches that we have collected, it is important to mention that, to the best of our knowledge, there are no previous and/or existing studies and publications that consider open data technology in Kuwait and especially in the private sector, which makes this study the first research that mentions open data concept in Kuwait so far. Some researchers are considering open data not only a strategy of sharing information but also an uncommon way for exchanging data especially in business field. In this study, they tried to check if it is possible to make data available in both private and public sectors. Research outcomes in [7] insured that there is no experience or awareness about open data technology and the organizations do not have any plans or thought toward using open data.

A qualitative researcher in [8] was introduced to investigate factors that motivated government institutions in Saudi Arabia for the adoption of OGD. In-depth semistructured interviews were used as a method for the qualitative assessment. Elements such as pillars, pressure, and rational myth were used from institutional theory to further deepen the study. In addition to the interviews, documentation was also utilized to support the qualitative outcomes. The study considered both public and private sectors. Major findings revealed that political reform; institutional pressures (both internal and external); wide range adoption of OGD among government agencies at local, regional, and international levels; and users' expectations were the major factors affecting the adoption of OGD.

A recent research in [9] was presented to investigate the prediction factors for the adoption of open data. The influencing factors were examined by employing UMEGA model which is particularly designed for e-government adoption. Three other factors were also considered such as imitating behavior of others, disregarding one's own beliefs, and grievance redressal. These factors were embedded in the proposed extended version of UMEGA model. A survey questionnaire was used for data collection from citizens of Pakistan. The outcome of the study suggested that factors such as facilitating conditions, effort expectancy, performance expectancy, and attitude have significant positive influence on effort expectancy, performance expectancy, attitude, and behavioral intention respectively to use open data technologies.

A new study in [10] was proposed to examine the factors influencing the adoption of OGD among firms in Taiwan. Factors such as top management support, government support, competitive pressure, perceived benefits, and perceived barriers were integrated based on sociotechnical model. A questionnaire was developed to collect needed data from respondents, the majority of them belonging to information technology firms. Results of the survey identified that top management support and competitive pressure are major factors that influenced the adoption of OGD by firms.

Researchers in [11] aimed to investigate factors that could affect the decision of an organization for open government data adoption in Saudi Arabia. They introduced an 


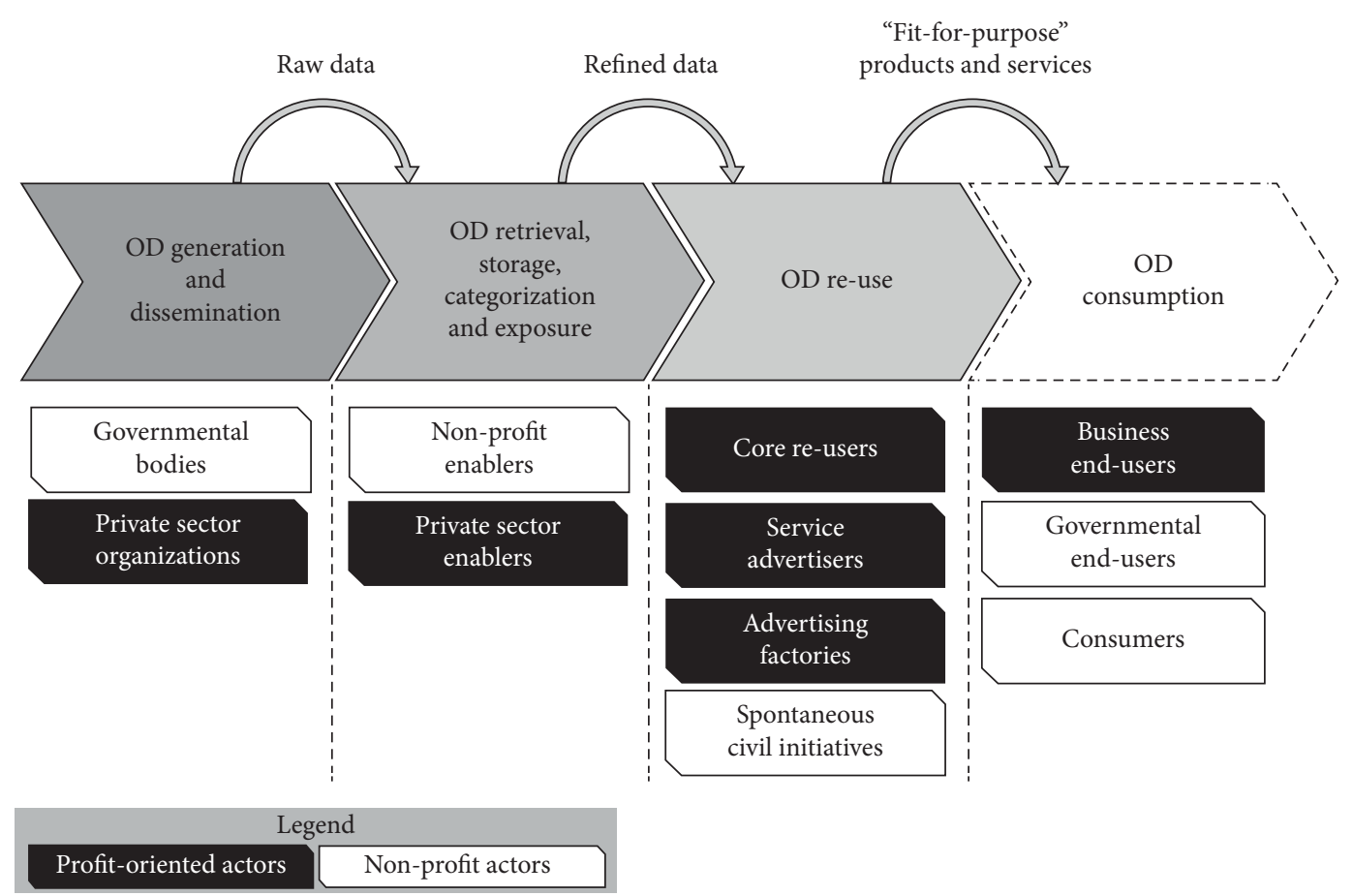

Figure 1: Open data value chain [4].

integrated model based on technology organization-environment framework and information systems success model. Three major factors were used to extend the two models: political leadership, culture, and open data intermediaries. The proposed model addressed major key factors that were missing in other literatures with the same scope. Moreover, the introduced model was formulated based on supply (represented by characteristics from the provider side) and demand perspectives (characteristics from the organization side).

Research on OGD in Bahrain was presented [12] to capture the motivations and impediments that influence government agencies behavior toward OGD publication. Besides, maturity level in the agencies participating in publishing open data was assessed. In addition, the research assessed the local consuming and reusing of OGD by investigating citizens' awareness, identifying citizens' needs, and determining key challenges. Two questionnaires were introduced to assess the supply and demand sides focusing on two different populations: all residents of the Kingdom of Bahrain and all government entities. The outcome of the survey suggested that supply and demand were major considerations when it comes to OGD assessment framework for the Kingdom of Bahrain.

Another recent study in [13] investigated the impact of OD on smart cities. Researchers proposed a theoretical framework by applying a systematic literature review. Lack of robust theoretical framework was the major reason to conduct this research. It consists of conceptual and experimental methodologies. Randomized controlled trial was used as an experimental research design tool to evaluate policy. Results of the study suggested that it is possible to evaluate the impact of OD initiatives. It also can be monitored and improved. Moreover, outcomes of this research can be considered as guidance for better understanding of OD initiatives on smart cities.

A study in [14] discussed the existence of the developed tools and technology to use open data to get the best results. Moreover, an important note that they consider is if the country allows for their people and scientists to use open data, they need to recognize the restrictions and rules that make the data available for them to use and modify. As a result, having a better view about the open data concept makes it easier for policy makers to demonstrate the picture on how to accept open data and apply it in the good way to get the best advantages for people and the country.

Researchers in [15] executed a mission that needed braveness from different sides and experts. They have created a path that contains some elements and basics to implement open data, which is called Open Data Implementation Guide (ODIG). (1) Effortlessness: this means the time that is needed to use is not extended. (2) Quick-win: this rule is about fast beginning improvement with different seen outcomes to help in validating and getting the proper backup from business owners. (3) Realization level: by mentioning the last concepts, this point gives the first proceedings in having the open government data developed. (4) Experience sharing: this is the opportunity to share knowledge between other governments for the development method. (5) Information release: it is collecting and gathering the data in its all shapes from the public agencies to make it available to all people.

A study on open data and how it can offer different chances for both enterprises and society was proposed [5]. Several sectors around the country can get the usefulness of open data concept, such as economic development, creativity, democracy, engagement, innovative products, and services. By considering the last benefits of open data, it is 
very essential for companies to take and implement the open data concept. Many researchers studied open data and the chance of choosing it as a competitive way between companies. Moreover, lots of studies pointed to the importance of identifying company resources and the proper method to use them as depicted in the OD resource model Figure 2. The source model suggests how to use data resources in the company. Researchers divided these resources into three parts which are information technology, information and data, and humans. The administration of all these partners requires the foundation of well-maintained partner systems.

A study in [16] pointed to the first movement toward information and data services availability. It began in the middle of 2000s in the European Union to enhance the knowledge about the importance of public open data by reutilizing it in 2003. There are many countries that have experienced open data technology and the first country was the United States of America (USA) in December 2009. After six months, the United Kingdom (UK) chose open data technology through implementing a website called data.gov.uk. With the last step of launching the website, UK is considered now as one of the top countries in using open data. In this study, they use the diffusion of innovation model to do their survey to the public sector, which concentrated on behavioral intentions of the users. The research ended with a conclusion that implementing open data in the public does not make any dangerous effect and can be trusted.

Authors introduced a research on open data portals in American cities [17]. Researchers have discovered that with the revolution of the Internet and exchanging knowledge and information, open data concept appeared to be one of the most modern names in information technology world ranking different places around the world. Since 2009, some researchers that were interested in open data concept tried to put some basic conditions on how open data must be alike and they presented it by eight propositions which are total, fundamental, appropriate, easy to get, machine-processable, nonpreferential, nonproprietary, and without authorization. Mentioning the last concept means that the data could be available to all without any hardness to reach and use. The priority of making open data is to give the opportunity for everyone to get its benefits and the most important thing is to cooperate faithfully to have the best result.

A study in [18] showed how implementing government open data in the UK is affecting the individuals in the country and its unexpected results. Researchers found that open data and its imaginable photo with the possible benefits that could happen by using it are very far and unbelievable from what they have discovered in UK. Furthermore, the most important thing they have mentioned is the bad use of open data that leads to a political goal for them. There are different advantages to use open data: (1) rising people and organization contribution, (2) making data more transparent, (3) and finally having information transference which means helping people getting the data more easily. Researchers have said that the results may be marked, particularly for an arrangement intensely dependent on innovations, initiatives, and tests. Open data is also more political than renovators claim.
Two researchers discussed the OGD and how recently government datasets are being more accessible and available for using information as nonproprietary groups, free of charge and with boundless utilization and dissemination rights. As it was mentioned in research [19] open data is a technology that made dreams come true for people who are seeking chances in health by making information broadly accessible to researchers, professionals, and scientists, but it needs a considerable fight to get the high quality and useful data. Authors in [20] also discussed open government data. They pointed to an important sentence which stated that to implement open data concept effectively, government must play a supportive part in this process. All businesses, either explicitly or implicitly, should employ a business model.

Researchers in [21] surveyed open data importance around different countries. Findings of the survey were interesting, especially the importance of open data and how much it is useful for the disciplinary community for solving social problems. Most important obstacles for publishing data as open data were the intent to publish results before releasing data, legal constraints, loss of credit, or field.

Open data could be an incredible development with recognition and possible misinterpretation and misuse. Measures must be taken to guarantee that all people have the right to use the data again and get more opportunities. In addition, researchers in [22] connected the open data concept with smart cities and pointed to the importance of supporting the smart cities with open data and the shape of them.

It can be seen from the reviewed researches that no study was dedicated on Kuwait. Furthermore, most of the studies were based on open government data but not on open commercial data. The reviewed literature lacks the ability to directly investigate if the private sector is independently eager to use its own open data to increase productivity and profitability. Accordingly, this research is undertaken.

\section{Research Hypothesis}

In this section, research hypotheses $\mathrm{H} 0, \mathrm{H} 1$, and $\mathrm{H} 2$ are introduced. Details related to each hypothesis are presented in the survey results.

$\mathrm{H} 0$ : most of the business owners are aware and have heard about open data technology and find it a solution for many problems (questions on section one).

$\mathrm{H} 1$ : most of the business owners are willing to apply the open data concept (questions on section two).

$\mathrm{H} 2$ : most of the business owners find the open data concept hard to use in Kuwait (questions on section three).

\section{Research Methodology}

In this part, the structure of this survey is presented. The questionnaire, information gathering, and data analysis are discussed.

4.1. Questionnaire Design. A questionnaire is introduced to 60 persons representing the private sector. The survey is designed to obtain information about the ability to accept open data technology and to measure if they are willing to 


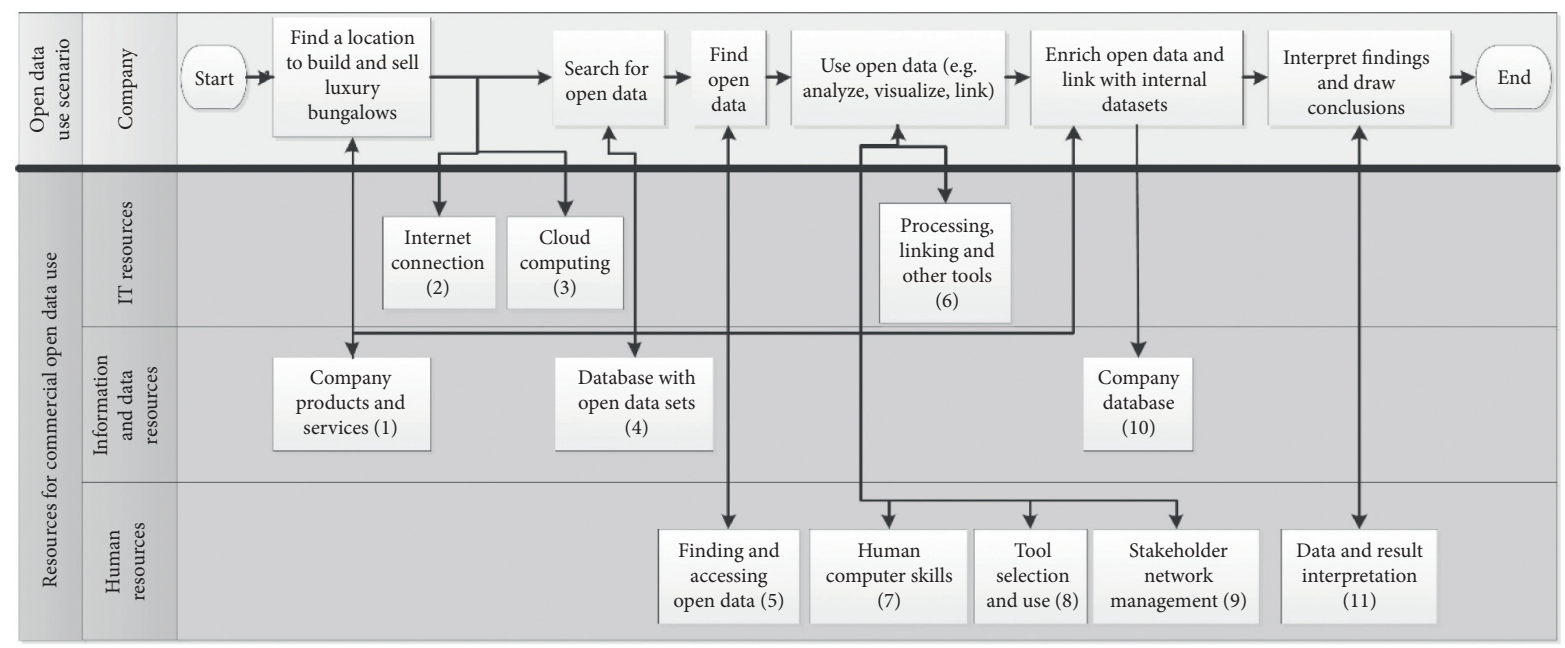

FIgURE 2: Open data resources model [5].

adopt this concept to enhance their business. We divided our survey into three sections to facilitate the process of collection and analysis of the results of the questionnaire as it is shown in Table 1. Section one focuses on the awareness of business owners toward open data concepts and their understanding. Section two considers the importance of applying open data and the possible benefits that will come from applying the technology. Finally, section three discusses some ideas and thoughts about applying open data and its future in Kuwait.

4.2. Data Collection. Survey methods were applied for gathering of primary data for the purpose of exploratory analysis. Making an electronic survey and hard copy were our two methods in distributing the survey. Online survey is an easy way to collect information because of the developed life that is based on the Internet and smart phones. Some respondents did not answer all the survey. These respondents were deleted from the sample. Some of the difficulties we had during the distribution process was finding people who have business and understand the meaning of OD concept. As a result, they took more than ten min to complete the questions and they left some questions without answers.

4.3. Research Instrument. The survey contained 24 questions, eight questions in each section. The survey was designed in both languages Arabic and English, for better understanding by everyone. Five-point Likert scale was used to know to which extent they agree with the statement, ranging from "strongly disagree" to "strongly agree" which was selected as a question type. The questionnaires were distributed to many places such as business companies, shops, and people who have their own business. Tools such as Microsoft Word (for creating hard copies) and Microsoft Forms (for creating the online version of the survey) were used. The online survey was sent through a link to people who were known and trusted to answer the questionnaire with credibility. The questionnaire was disseminated between November and December 2019.

\section{Survey Results}

This section demonstrates results after data collection for the three questions' sections. We present the results and the answers of business owners to analyze them to observe the acceptance of applying open data technology. We reviewed each section and discussed the most critical questions that contained the best opinions and thoughts of business owners.

5.1. Section One. In this section, knowing the educational level of the respondents for understanding the OD concept is essential to add more value to our study and to enhance the results. The section contains eight questions. Each question aimed to understand if the business owner was aware and knew the OD concept in advance. Below we illustrate two questions that were helpful to the results in this part.

5.1.1. Question Number One (Q1). In this question, we ask the business owners if they have heard about the OD concept before and if they are familiar with it. As shown in Figure 3 the results illustrate that around $51 \%$ and above of business owners know about OD concept and they feel it is not new to them. Such an information provided a good impression about the level of understanding of the OD concept. The results are shown as follows: $51 \%$ agree, $17 \%$ strongly agree, $20 \%$ neutral, $7 \%$ disagree, and 5\% strongly disagree.

5.1.2. Question Number Two (Q2). In this question, we tried to know if the business owners (from their understanding of the open data concept) think that the open data concept is a tool to open chances and opportunities for them in enhancing their business. It is essential to understand how business owner are thinking toward open data concept from their knowledge and perspective. This question aims to explain the business owner thinking about OD technology and if this technology can affect their business and can be a different experience. Figure 4 shows how many business 
TABLE 1: Survey questions divisions.

\begin{tabular}{lcc}
\hline Section & Question no. & Description \\
\hline One & Q1 and Q2 & Measure the business owner's knowledge and awareness of OD \\
Two & Q3 and Q4 & Shows the importance of applying OD in the business owner's company \\
Three & Q5, Q6, and Q7 & OD and its future in Kuwait \\
\hline
\end{tabular}

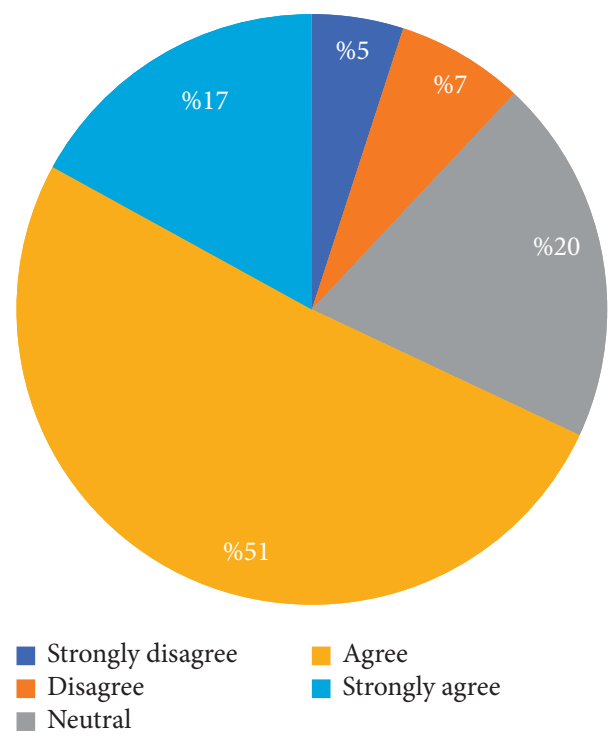

FIgURE 3: Q1: I think the open data concept is common and I heard about it before.

owners agree with this statement and most of them strongly agree on the great effect of OD technology. The results are shown as follows: $30 \%$ strongly agree, $34 \%$ agree, $23 \%$ neutral, $8 \%$ disagree, and 5\% strongly disagree.

5.2. Results of Section One. From the results of the questions, the answers that we collected from business owners were varied and enormous in thought and understandings toward OD concept. It was very clear that knowing OD technology can guide business owners to think about its advantages on their business.

5.3. Section Two. In this section, we tried to introduce questions to measure how business owners can find the OD concept important to them, if they will accept applying it in future, if they find it as a bad influence, and if it has a none effective change to their work and company. Each question aimed to check the business owner thoughts towards OD concept and if it can be an advantage stage for his business. The section contains eight questions. Down below, we selected two questions that were helpful to the results in this part.

5.3.1. Question Number Three (Q3). As shown in Figure 5, a business owner responded in a very good way with this question and found OD as a tool to solve problems in their business. It is very clear that most of them agree on the statement and consider the OD technology to be a way to

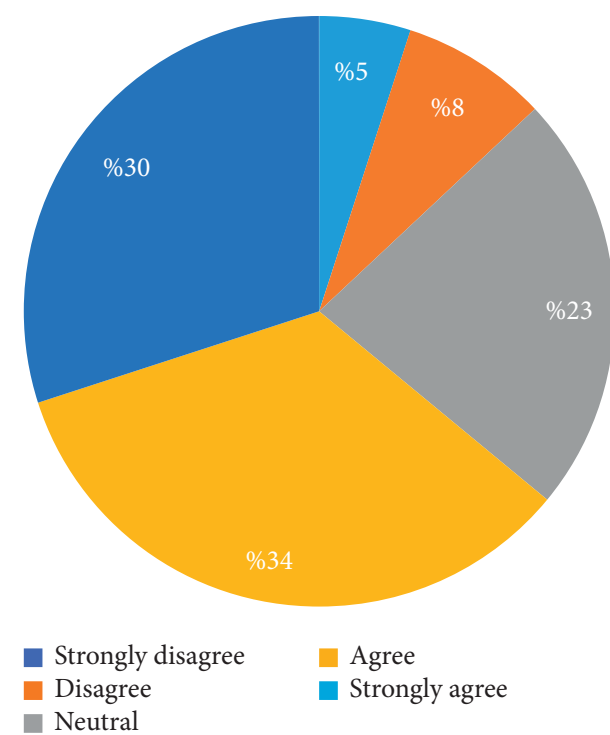

FIgURE 4: Q2: I think open data can make a huge difference.

enhance their business and make their work better and far from mistakes and problems that may happen to their business. The results are illustrated as $25 \%$ strongly agree, $33 \%$ agree, $25 \%$ neutral, $14 \%$ disagree, and 3\% strongly disagree.

5.3.2. Question Number Four (Q4). As shown in Figure 6, there was a different point of view in answering the question. Some of the business owners found that the OD concept can increase the productivity in a positive direction, and some other business owners think that it will not be affecting the economic side of their business in a good way. The answers point to an important note that some of the business owners cannot trust the open data technology to be applied in their business. The results are shown as follows: $38 \%$ agree, $16 \%$ strongly agree, $21 \%$ neutral, $23 \%$ disagree, and 2\% strongly disagree.

5.4. Results of Section Two. From the answers of business owners, it can be seen that most of them can accept applying the open data concept to add a new value for their work. Moreover, some of the business owners find the OD technology as not trusted and cannot add anything to their work and their business.

5.5. Section Three. This section is essential because it will discuss the OD technology and if there is any chance to apply it in Kuwait by the business owners in the private sector. In Kuwait, having OD technology can be a substantial step in 


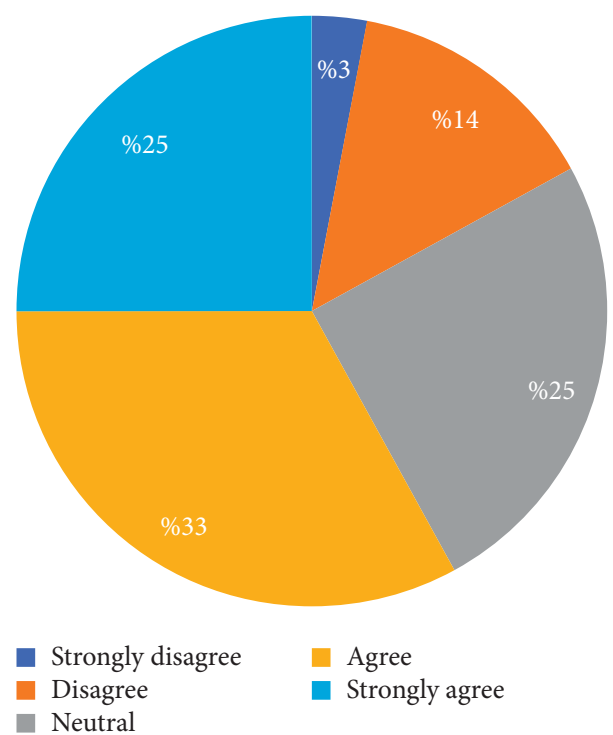

FIGURE 5: Q3: I think applying open data will reduce time, human errors, and problems.

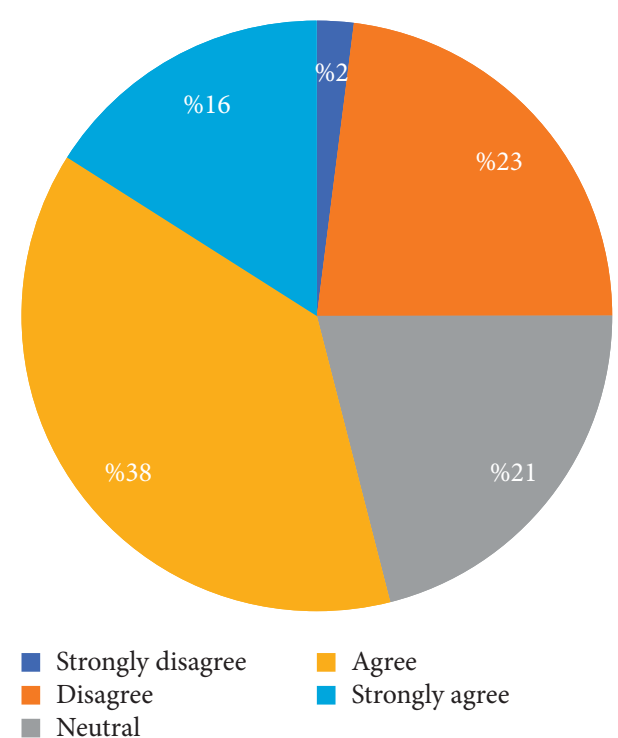

FIGURE 6: Q4: I think applying open data in my company will affect the productivity process upwards.

the business field and need a big acceptance from the stakeholders. We added this section to understand and measure how business owners are having the intention to add the concept in their work and find it as a new experience and a way to enhance their business.

5.5.1. Question Number Five (Q5). As shown in Figure 7, we ask the Business Owners if they think the OD technology can be implemented very easily in Kuwait without any difficulties and problems. The answers were very negative than what we have expected and most of business owners think that it is so hard to apply open data in Kuwait and cannot be accepted and be used. Other answers agreed with the

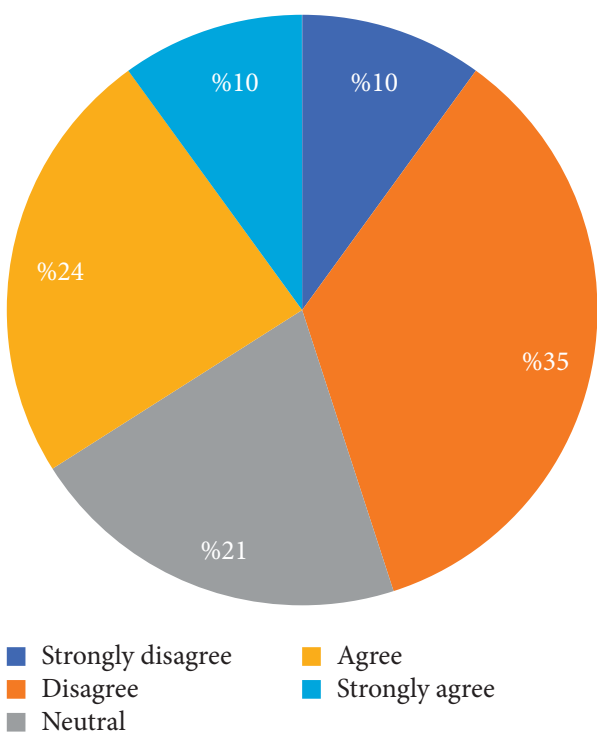

FIGURE 7: Q5: I think open data can be easily implemented in Kuwait.

statement and think that the OD technology can be used very easily in Kuwait as a new way of doing work. There are business owners who did not know if they agree with the statement or disagree with it, so they decided to be in between and choose neutral. The results are shown: $24 \%$ agree, $10 \%$ strongly agree, $21 \%$ neutral, $35 \%$ disagree, and $10 \%$ strongly disagree.

5.5.2. Question Number Six (Q6). As shown in Figure 8, we tried to measure business owners' thoughts about the OD technology and if it will need a large support and acceptance in Kuwait. It was very clear to business owners that they strongly agree with this statement while few respondents think that OD does not need support to apply in Kuwait and it can be easily implemented without any encouragement. This gives us a clear view that open data in Kuwait cannot be implemented successfully without any encouragement and help. The results are as it is shown: $28 \%$ agree, $32 \%$ strongly agree, $12 \%$ neutral, $19 \%$ disagree, and $9 \%$ strongly disagree.

5.6. Results of Section Three. From the feedback that we have got from business owners in this section, there were substantial differences about the idea of accepting open data technology and if this technology can occur in the business world. Some of the answers were very positive about having the technology in Kuwait and other answers were very far from what we have expected. In addition, business owners are finding it difficult to adopt and apply the new technology without support.

\section{Recommendations}

Open data technology is a considerable concept that needs big understanding and support from business owners. Understanding the OD concept very well can give us a big hope to implement it in Kuwait. From our study, we 


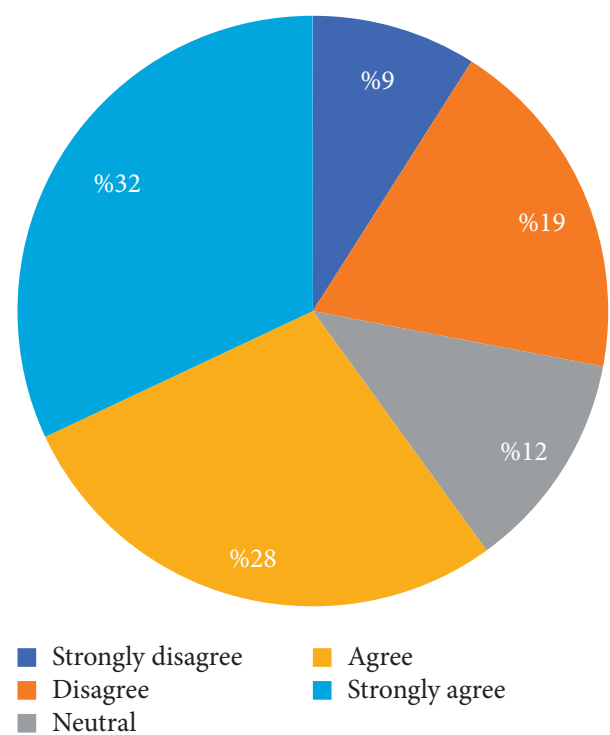

FIGURE 8: Q6: I think applying open data in Kuwait will need large support and understanding.

recommend that spreading the knowledge about OD technology is essential to raise the OD educational level. Furthermore, it is essential to consider that OD technology can be a new move in the business field and enhance the investments.

\section{Future Works}

In the future, it is essential to enhance the knowledge of open data concept through doing more studies and researches in Kuwait in both public and private sectors. Moreover, adding a proposed system of OD technology will promote this concept and increase the awareness about it. Furthermore, concentrating on the advantages of open data technology is very essential to achieve better results in future studies and to support them for the countries that succeed in implementing the technology to take these countries as a good example for using OD technology and showing models for governments that have failed in implementing this technology. In addition, an open data strategy must be proposed and be adopted by, first, the government. Staging the OD execution via welldefined framework has valuable deliverables (Ministry of Interior started displaying number of traffic deaths in real time as part of traffic awareness strategy). This action can drive other entities such as the private sector to gradually think of OD. NGOs as well can play a significant role to promote OD in different occasions. It is important in future to highlight what are the most important factors that influence business owners to adopt OD (as OD supplier).

\section{Conclusion}

OD technology is one of the important concepts nowadays in the information technology world. This research focused on the open data definition and the ability of applying this technology in Kuwait, especially in the private sector. This study discussed business owners' opinions about OD via a survey. By discussing the hypothesis and the results that we had from the surveys, it was very clear that the majority of business owners have sufficient knowledge about OD technology and know about the concept. Furthermore, most of the business owners' answers do support the idea of adopting open data technology, but some of them are not encouraged to implement OD in their business. Another important note that we must point to is that business owners in Kuwait have weak intention to apply open data without support. Also, the results have shown that OD cannot be implemented easily in Kuwait and its future is not structured well. We believe that the private sector's adoption of the idea of open data as a source of income and productivity will positively affect the economic cycle in the country and encourage the government sector to support the concept of open data and enact the necessary laws for that.

\section{Data Availability}

The data were collected using hard copy and soft copy. Soft copy is based on an online survey system. The data associated with this study are survey/questionnaire data. The questionnaire is of type Five-Points Likert Scale. The survey data used to support the findings of this study have been deposited as a record in the Fairsharing.org repository. The data are available for anyone to access (via the URL) for research purposes only https://forms. office.com/Pages/AnalysisPage.aspx?id=DQSIkWdsW0yxEjajB LZtrQAAAAAAAAAAAAMAAABXHIZUQkRPREYyNFhZ QTM3VUpFQ1NQN0RBSDRVQi4u\&AnalyzerToken=Bq wlzwRwtpTv3kpafIqQTaWXwwkHqysQ.

\section{Conflicts of Interest}

The authors declare that they have no conflicts of interest.

\section{References}

[1] D. Hasegawa and Y. Asano, "Latest trends and future outlook for open data: making public-sector data available to the private sector," Hitachi Review, vol. 65, no. 1, pp. 724-728, 2016.

[2] V. Gewin, "Data sharing: an open mind on open data," Nature, vol. 529, no. 7584, pp. 117-119, 2016.

[3] A. Vetrò, L. Canova, M. Torchiano, C. O. Minotas, R. Iemma, and F. Morando, "Open data quality measurement framework: definition and application to Open Government Data," Government Information Quarterly, vol. 33, no. 2, pp. 325337, 2016.

[4] Y. Charalabidis, A. Zuiderwijk, C. Alexopoulos, M. Janssen, T. Lampoltshammer, and E. Ferro, "Open data value and business models," The World of Open Data, Springer, vol. 28, pp. 115-136, 2018.

[5] A. Zuiderwijk, M. Janssen, K. Poulis, and G. van de Kaa, "Open data for competitive advantage: insights from open data use by companies," in Proceedings of the 16th Annual International Conference on Digital Government Research, pp. 79-88, New York, NY, USA, May 2015.

[6] N. Alawadhi, I. A. Shaikhli, A. Akandari, M. Tahir, and T. Nanoscience, "Optimal path planning for urban vehicles using Internet of things: a new navigation perspective," 
Journal of Computational and Theoretical Nanoscience, vol. 16, no. 3, pp. 1074-1080, 2019.

[7] A. Herala, J. Kasurinen, and E. Vanhala, "Views on open data business from software development companies," Journal of Theoretical and Applied Electronic Commerce Research, vol. 13, no. 1, pp. 91-105, 2018.

[8] M. S. Altayar, "Motivations for open data adoption: an institutional theory perspective," Government Information Quarterly, vol. 35, no. 4, pp. 633-643, 2018.

[9] M. M. Khurshid, N. H. Zakaria, M. I. Arfeen, A. Rashid, and M. Q. Siddiqui, "Predictors for the adoption of open data technologies," RMC Journal of Social Sciences and Humanities, vol. 1, no. 3, pp. 1-13, 2020.

[10] H.-J. Wang and J. Lo, "Factors influencing the adoption of open government data at the firm level," IEEE Transactions on Engineering Management, vol. 67, no. 3, pp. 670-682, 2019.

[11] A. Alhujaylan, L. Car, and M. Ryan, "An investigation of factors influencing private technology organizations' intention to adopt open government data in Saudi Arabia," in Proceedings of the 2020 10th Annual Computing and Communication Workshop and Conference (CCWC), pp. 06540661, Las Vegas, NV, USA, January 2020.

[12] A.-K. Katbi and J. Al-Ammary, "Open government data in kingdom of Bahrain: towards an effective implementation framework," in Proceedings of the World Conference on Information Systems and Technologies, pp. 699-715, Galicia, Spain, April 2019.

[13] F. T. Neves, M. de Castro Neto, and M. Aparicio, "The impacts of open data initiatives on smart cities: a framework for evaluation and monitoring," Cities, vol. 106, p. 102860, 2020.

[14] A. Zuiderwijk, M. Janssen, and Y. K. Dwivedi, "Acceptance and use predictors of open data technologies: drawing upon the unified theory of acceptance and use of technology," Government Information Quarterly, vol. 32, no. 4, pp. 429-440, 2015.

[15] M. Solar, L. Meijueiro, and F. Daniels, "A guide to implement open data in public agencies," Lecture Notes in Computer Science, in Proceedings of the International conference on electronic government, pp. 75-86, Koblenz, Germany, September 2013.

[16] V. Weerakkody, Z. Irani, K. Kapoor, U. Sivarajah, and Y. K. Dwivedi, "Open data and its usability: an empirical view from the Citizen's perspective," Information Systems Frontiers, vol. 19, no. 2, pp. 285-300, 2017.

[17] J. Thorsby, G. N. L. Stowers, K. Wolslegel, and E. Tumbuan, "Understanding the content and features of open data portals in American cities," Government Information Quarterly, vol. 34, no. 1, pp. 53-61, 2017.

[18] B. Worthy, "The impact of open data in the UK: complex, unpredictable, and political," Public Administration, vol. 93, no. 3, pp. 788-805, 2015.

[19] E. G. Martin, J. Law, W. Ran, N. Helbig, and G. S. Birkhead, "Evaluating the quality and usability of open data for public health research: a systematic review of data offerings on 3 open data platforms," Journal of Public Health Management and Practice, vol. 23, no. 4, pp. e5-e13, 2017.

[20] F. A. Zeleti, A. Ojo, and E. Curry, "Exploring the economic value of open government data," Government Information Quarterly, vol. 33, no. 3, pp. 535-551, 2016.

[21] B. Schmidt, B. Gemeinholzer, and A. J. P. . o. Treloar, "Open data in global environmental research," The Belmont Forum's Open Data Survey', vol. 11, no. 1, Article ID e0146695, 2016.

[22] A. Ojo, E. Curry, and F. A. Zeleti, "A tale of open data innovations in five smart cities," in Proceedings of the 2015 48th Hawaii International Conference on System Sciences, pp. 2326-2335, Kauai, HI, USA, January 2015. 